\title{
Investigation and diagnosis of a reinforced concrete reservoir with intense crack formation from several sources
}

\author{
M. Sollero ${ }^{1}$ [ $\cdot$ H. Bolorino ${ }^{1}$
}

Received: 29 June 2016/Accepted: 28 September 2016/Published online: 20 October 2016

(C) Springer International Publishing Switzerland 2016

\begin{abstract}
This article presents an investigation of the pathological condition of a wastewater reservoir, characterized by leaks, severe cracking-typically due to expansive reactions of the concrete-and deterioration of the protection system. The investigation was based on a visual inspection, anamnesis, national and international literature review, project analysis and implementation of tests to determine the corrosion potential, chloride content, resistance to axial compression and modulus of elasticity of the concrete, as well as the occurrence of expansive reactions by petrographic analysis and scanning electron microscopy, etc. The contribution of various phenomena towards the development of the reported condition were detected, the main ones being the thermal shrinkage of the concrete, the limit of opening of cracks adopted in the project and the premature use of the structure. Based on the diagnosis developed, we studied the prognosis of the structure and prepared recommendations for recovery, mitigation and protection of the elements that make up the reservoir. The study brings the results of a complex and interdisciplinary process required for the proper diagnosis of the causes of degradation of a structure, on which the success of the recovery measures depends.
\end{abstract}

Keywords Inspection - Concrete - Fissuration AAR . DEF

M. Sollero

marcela.barros@concremat.com.br

1 CONCREMAT Engenharia e Tecnologia S.A., 13771, Avenida das Nações Unidas Bloco 1, $6^{\circ}$ andar, São Paulo, SP, Brazil

\section{Introduction}

Concrete structures must meet the quality requirements related to the aspects of durability, functionality and stability. In the case of reservoirs and other structures designed to contain water and other liquids, these requirements can be interpreted as the need for the structure to remain free from any damage that could compromise its water-tightness, its resistance and the safety of the direct or indirect users for the lifespan for which it was designed-in general, at least 50 years $[1,2]$.

This article presents the investigation of the pathological condition found in a half-buried wastewater reservoir, with a storage capacity of $4300 \mathrm{~m}^{3}$, designed in 2003 and built in 2004. The superstructure of the reservoir is composed of a wall, lower slab and upper beam executed in reinforced concrete, molded in loco. According to the specifications of the project, the reservoir also has an internal diameter of $20.0 \mathrm{~m}$, a height of approximately $15.1 \mathrm{~m}$-with $1.6 \mathrm{~m}$ buried-and $\mathrm{f}_{\mathrm{ck}} \geq 30 \mathrm{MPa}$. Brazilian standard ABNT NBR 6118 [3] defines the environment in which the reservoir is located is classified as Aggressively Class III, that is, Strong.

The structure under study was, in the period of inspection, severely cracked, and leaking, as shown in Figs. 1 and 2.

\section{History}

The survey of the structure's history was carried out through the study of documents such as reports, projects and reservoir calculation spreadsheets, as well as the information provided by the owners.

Leaks and fissuration of the structure were observed right after the completion of the project, in 2004. 
Fig. 1 Overview (a) and partial view (b) of the reservoir-2013

Fig. 2 Fissuration details on the reservoir wall. Note also the presence of failure in watertightness and deterioration of the coating
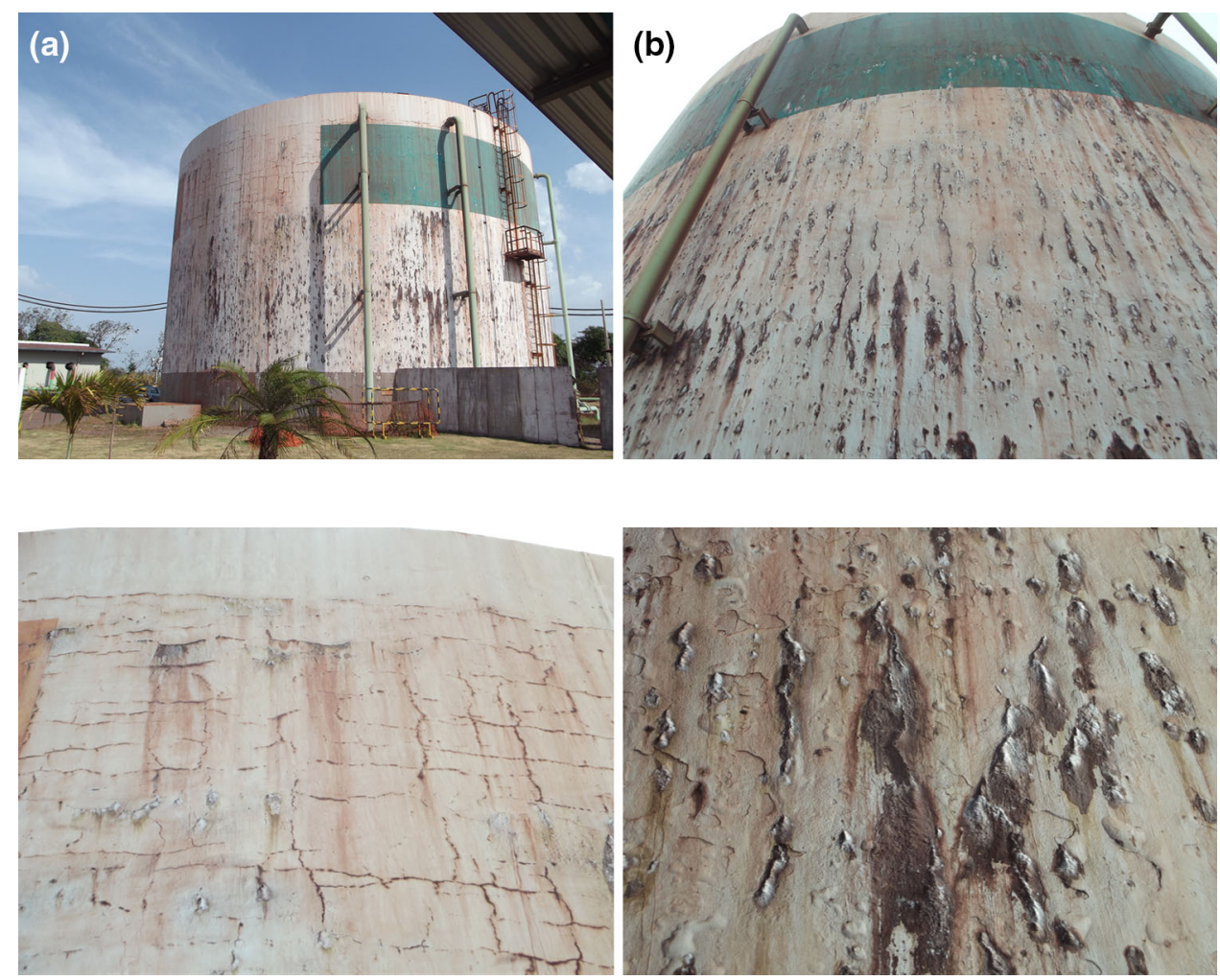

Fig. 3 Overview (a) and partial view (b) of the reservoir-2009


According to information obtained by the owner, the reservoir was put under stress-entered into service-after less than 28 days and the cure was probably deficient. However, there are no technical records about the execution of the work, such as technological control reports, or about the waterproofing used at the time.

In order to remedy the failure in the water-tightness of the structure, waterproofing was performed with the application of an asphalt mantle, the ineffectiveness of which was demonstrated by the leaks appearing in the structure since then. We were also informed that the asphalt mantle probably did not adhere properly to the substrate, inside the reservoir, because it was damp during its application. Since then, the reservoir has not been emptied for inspection or maintenance.
Later, in 2009, the reservoir underwent an inspection that evaluated the pathological manifestations present in the structure and replacement of the waterproofing system was recommended. Figures 3 and 4 show the reservoir in 2009, 5 years after its construction.

The following year, in 2010, the reservoir received a coating on the outside-an epoxy-based primer and polyurethane finish (waterproofing protection system).

Given the state of degradation of the reservoir and the observance of an alkali-aggregate reaction (AAR) in other structures of the same complex, a new tactile-visual inspection was carried out in April of 2013, which found, in addition to the previously mentioned anomalies, the blistering of the coating due to the accumulation of water between the protection system and the reservoir. One could 
Fig. 4 Details of the reservoir wall presenting fissuration and water percolation


also observe the absence of crumbling concrete or hollow sounding spots, in a preliminary examination. The formation of cracks and the exudation of a whitish material, which may be the result of the leaching of concrete salts or of expansive reactions of the material, led to the development of a more detailed study, which the current article is based on.

\section{Theoretical reference}

Sections 3.1-3.3 present a summary of the bibliographic review conducted, focused on the main knowledge necessary for the proper understanding of the pathological condition diagnosed in the reservoir.

\subsection{Shrinkage of the concrete}

The shrinkage of the concrete in its plastic or hardened state, especially early on, can generate linear or mapped fissuration [4, 5]. Sections 3.1.1-3.1.3 differentiate the hydraulic shrinkage, by drying and heat, which are the main forms of this phenomenon.

\subsubsection{Hydraulic shrinkage of the concrete}

Hydraulic shrinkage of the concrete results from the volumetric changes induced by the loss of water from the concrete during its hardening and the restrictions imposed by the binding with other elements or by the reinforcements themselves. If the stress generated by this interaction is greater than the resistance to the traction of the concrete, linear and generally parallel cracks are generated [5].

We emphasize that standard ACI 224.1R-07 [5] classifies autogenous reaction, characterized by the self-desiccation of the concrete, with a water/cement ratio below 0.42 , as a type of hydraulic shrinkage.

\subsubsection{Shrinkage by drying of the concrete}

Shrinkage by drying of the concrete, which may be considered a type of hydraulic shrinkage occurs when the superficial layer of the element undergoes an energetic drying in the first few hours after its execution-usually due to deficiency in the curing process, generating a fissuration with a mapped-out formation and little depth $[4,5]$. The occurrence and the frequency of the shrinkage by drying are influenced by the water/ cement ratio, by the type of cement and by the environmental conditions, among other factors [4].

\subsubsection{Thermal shrinkage of the concrete}

Cracks produced by thermal shrinkage occur through two processes: creep followed by shrinkage or differential shrinkage, as explained by Cánovas [4].

One starts from the principle that the hydration reactions of the cement are exothermic, that is, they produce heat. The amount of heat produced is defined by the heat from hydration of the materials used, by the dosage applied and by the volume of the concrete poured; the temperature reached by the concrete is related to the amount of heat generated at room temperature. Depending on the temperature rise, the concrete expands, still in a plastic state. Since the material has low thermal conductivity, it slowly cools down. The cooling stage of the concrete until balance with the room temperature is usually achieved when the material has already hardened, but with no resistance to traction-and, therefore, to fissuration-enough to absorb the stresses generated by the volumetric variations.

The cracks formed by this process are often deep and have a mapped or linear formation, influenced by the moment at which they occurred, the intensity of the shrinkage, the elasticity modulus, the distribution and the amount of reinforcement in the concrete.

In the case of differential shrinkage, it involves the formation of high thermal gradients between the deeper and more superficial layers of large elements. As a result, cooling and differential shrinkage occur between the various depths concreted. When overcoming resistance to the traction of the concrete, shrinkage causes cracks that are commonly distributed in a reticular form, evolving until the thermal balance is achieved, which can extend for long periods, penetrating more deeply into the elements $[4,5]$. 


\subsection{Expansion reactions of the concrete}

The expansion reactions of the concrete cause damaging effects as from the moment in which the stress generated causes effects such as fissuration, flaking, chipping and deformations, among other things. Such reactions may result from the attack by sulfates, the alkali-aggregate reaction and the late hydration of free $\mathrm{CaO}$ and $\mathrm{Mg}$. Sections 3.2.1 and 3.2.2 briefly explain the expansion mechanisms of concrete due to the attack by sulfates and the alkali-aggregate reaction.

\subsubsection{Concrete expansion by sulfates}

The attack by sulfates may stem from an external source, such as contact with contaminated water, or an internal one, when material with excessive sulfates was used when making the concrete, or when there is the formation of gypsum or secondary or delayed ettringite (DEF).

Ettringite, a component formed during the hydration of concrete, loses stability from about $65^{\circ} \mathrm{C}$, decomposing into monosulfate hydrate; the sulfate ions released in this process are adsorbed by the hydrated calcium silicate. Later, with the concrete hardened, contact with moisture can dissolve the sulfate ions, causing the late formation of ettringite, a whitish, crystalline material, when viewed with the naked eye.

The growth of the crystals generates stresses as well as the adsorption of water in an alkaline medium by a slightly crystalline ettringite, according to the hypotheses most commonly accepted by the academic world. The stresses generated by the expansion, in turn, generate the fissuration of the concrete. As the cracks open the way for the penetration of more moisture, the reaction tends to be continuously accelerated in the absence of interventions [6].

\subsubsection{Alkali-aggregate reaction}

The reaction between reactive minerals of the aggregates, the alkali and hydroxyl ions from cement paste results in the formation of alkaline silicate gels, depending on the disorder in the crystalline structure of the aggregates, porosity and particle size. The attack on the concrete is based on the depolymerization of the silica structure and on the adsorption of metallic ions on the surfaces of the products of the reaction, as indicated by Mehta and Monteiro [6].

The gel absorbs water by osmosis and expands, creating a pressure equivalent to up to $4 \mathrm{MPa}$ inside the concreteif the degree of restriction is low, the pressure implies the expansion of the concrete and fissuration, and could eventually reach a point at which the structure is completely deteriorated [5-7]. Based on this principle, one of the most used mitigation solutions of the AAR effects is the confinement of the elements, by applying compressive stresses to the concrete.

The typical configuration of the cracks generated by AAR is mapped, and may be in the direction of the reinforcements, forming a track with lines parallel to it. In addition to the fissuration, the alkali-aggregate reaction can cause the exudation of gel, chipping, deformation, discoloration, reduction of resistance to compression and of the elasticity modulus, among other items [7].

Standard ABNT NBR 15577-1 [8] sub-divides the alkali-aggregate reaction into alkali-silica, alkali silicatea type of alkali-silica reaction - and alkali carbonate.

Standard ACI 201-2R-08 [9] sub-divides the alkali-silica reaction into two categories: one with reactions involving slightly crystalline or metastable siliceous materials and one with reactions involving certain varieties of quartz. In the first type, the expansion and fissuration usually become visible between 5 to 10 years after the construction; in the second type, the manifestations of reaction take longer to become apparent and it can last for many decades.

\subsection{Opening limit of cracks}

The fissuration of reinforced concrete elements is seen as inevitable, given the specific characteristics of the material [3]. However, concrete fissuration may result in damage related to aesthetical, durability and safety aspects of the structures, as well as to the sense of security by users-the so-called sensory acceptability - and to the functionality of the elements, in the case of structures where being leakproof is a requirement. In order to get a good performance in relation to these aspects, national and international standards seek to define maximum limits for the opening of cracks, to be incorporated into the design of the structure.

Since its revision, published in 2003, shortly after the completion of the reservoir project, standard ABNT NBR 6118: 2014 [3] defines maximum limits for the opening of cracks in concrete structures based on the Class of Environmental Aggressivity, aimed at the protection of rebars in relation to corrosion. For reinforced concrete structures in an environment with Environmental Aggressivity Class III, such as the reservoir under study, the maximum recommended opening of cracks is $0.3 \mathrm{~mm}$. In spite of highlighting that this limit should be regarded only as a criterion for the appropriate project of structures and that the real crack openings may eventually exceed the reference value, the standard also states that in the case of reservoirs, smaller opening limits should be adopted in order to preserve their watertight qualities. In the version which was in force at the beginning of the reservoir project, standard ABNT NBR 61181980 [10] defined the opening 
limit as $0.1 \mathrm{~mm}$ for unprotected structures in an aggressive environment and as $0.3 \mathrm{~mm}$ for protected structures. The adoption of $0.15 \mathrm{~mm}$ as the opening limit of cracks in reservoirs is also common, as shown by Guimarães [11].

The American standard ACI 224-R01 [12] indicates, as a reasonable opening limit for cracks in structures designed to contain water, the value of $0.1 \mathrm{~mm}$. The document states that it is expected that a portion of the cracks of the structure exceed this value, and one should use this value only as a reference, but it emphasizes the need to adopt opening limits for cracks that are more restrictive, in structures whose contact with moisture is constant or where leaks are a concern.

British Standard BS 8007: 1987 [13], focused on the design of structures for the containment of liquid, determines the maximum value of $0.2 \mathrm{~mm}$ for the opening of cracks in elements with severe or very severe exposure. The standard was replaced by the Eurocode [14] in 2006, which adopts a slightly more complex classification, and relates the opening of cracks to the thickness of the walls and the hydrostatic pressure, but limits the maximum opening to $0.2 \mathrm{~mm}$ in structures in which leaks must be limited or not permitted. With this value, it is expected that the crack be sealed naturally by the crystallization of the salts of the concrete in a short period, thus preserving the water-tightness of the structure.

\section{Methodology}

The investigation of the pathological condition was structured in the following steps:

(a) Survey of the history of the structure/anamnesis;

(b) Visual inspection and registration of anomalies;

(c) In loco tests and collection of samples for laboratory testing;

(d) National and international bibliographic review;

(e) Analysis of the data obtained;

(f) Elaboration of a diagnosis, prognosis and proposal of therapy.

It is noteworthy that, due to logistical issues, it was not possible to empty the reservoir and, therefore, its internal area was not inspected.

Tests and analyses were conducted by multi-disciplinary teams, formed by civil engineers, geologists, technologists in civil construction and chemists.

\section{Results obtained}

The results obtained by visual inspection and tests performed are presented in Sects. 5.1, 5.2 and 5.3.

\subsection{Visual inspection}

Through the visual inspection, it was found that the structure presents a condition of generalized fissuration on the reservoir wall, with percolation of water, efflorescences and concretions. The cracks have a maximum opening of $0.5 \mathrm{~mm}$. On the upper face of the beam, one could see the occurrence of transverse cracks with systematic distribution.

The presence of points of segregated concrete under the coating was found, as shown in Fig. 5.

It is necessary to highlight that the presence of red spots at points affected by infiltrations was not considered indicative of the presence of oxides and corrosion of embedded rebars, given it is the same coloration as the wastewater stored in the reservoir. The structure does not show evidence of the corrosion of the rebars, such as the disgregation of the concrete. For confirmation, prospecting for rebars at intervals along the wall was performed. In all the regions analyzed, the rebars was in good conditions, as shown in Fig. 6.

One could also note water retention between the surface of the walls and the epoxy and polyurethane based waterproof coating, a situation responsible for the formation of blisters and its bloated appearance. Figure 7, in which one may observe the percolating of water after drilling the coating, illustrates this conclusion.

The inner area of the tank cannot be inspected, given that the logistics of emptying it are not practical. Figure 8 displays, however, the details of the limit of the waterproofing inside the structure.

\subsection{Technological tests}

The testing and collection of samples were carried out at intervals along the reservoir wall, which had its height and

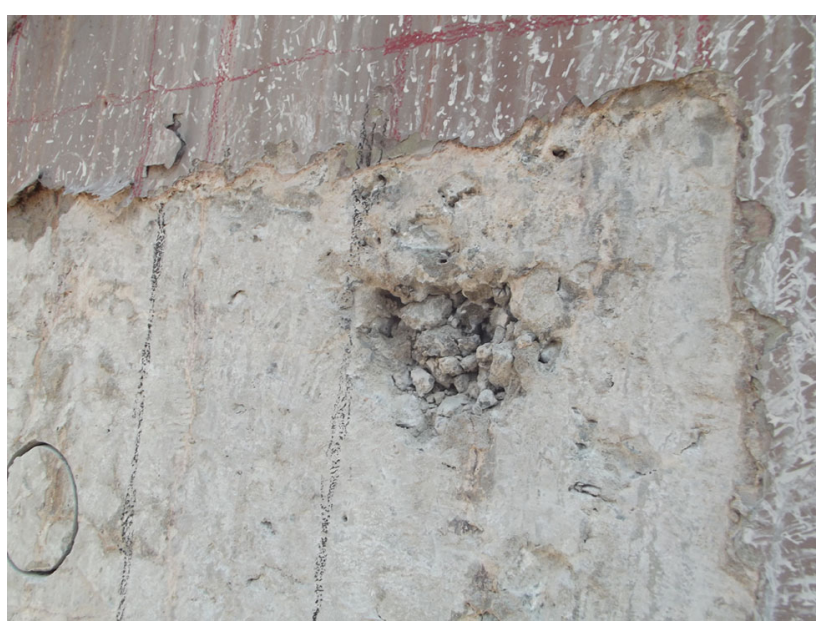

Fig. 5 Segregated concrete point visualized after a partial removal of the coating 
Fig. 6 Detail of rebar built into the concrete

Fig. 7 Wall detail immediately before (a) and after the commencement of drilling (b), at which time one may observe the percolation of water trapped between the coating and the structure

Fig. 8 Limit of the internal waterproofing approximately $60 \mathrm{~cm}$ below the top of the structure. We also observe the color of the water
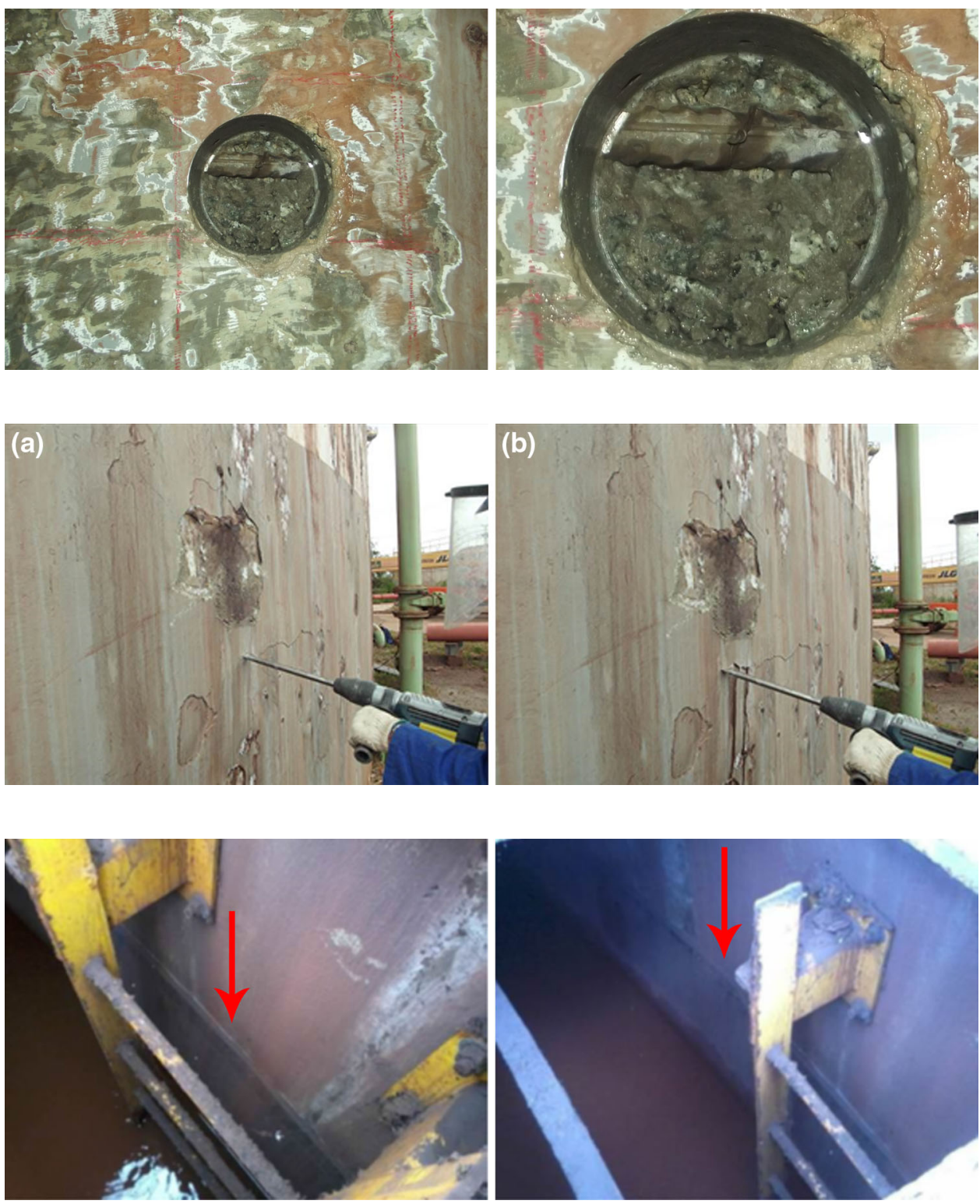

its length divided into 3 parts each, delimiting 9 quadrants. It is noteworthy that, with the exception of the specimens for the determination of expansive reactions of the concrete, the tests and collection of samples were carried out at points with no visually identifiable anomalies.

The results of the technological tests are summarized in Table 1.

\subsection{Opening of cracks}

According to Guimarães [11], to ensure the watertightness of reinforced concrete reservoirs, one must restrict the opening limit of cracks (wk) at $0.15 \mathrm{~mm}$, under the combination of nearly permanent loading actions. The bibliographical review revealed opening limits of from 0.1 to $0.2 \mathrm{~mm}$ in international standards.
The calculation spreadsheets and other reference documents of the structure did not present records of verification of the openings of cracks. Thus, in addition to the evaluation of the structure, we decided to calculate the crack opening based on information provided by the calculation spreadsheets and the designs.

The calculation spreadsheets showed only calculation requests $\left(\mathrm{N}_{\mathrm{d}}\right)$ for verification of the ultimate limit state (ULS), but the verification of the opening of cracks must be calculated for the serviceability limit state (SLS). Hence, we started with the premise that the weighting coefficients $\left(\gamma_{\mathrm{q}}, \gamma_{\mathrm{ge}}\right)$ were adopted as being equal to 1.4 and we obtained the serviceability request $\left(\mathrm{N}_{\mathrm{d}}\right.$, serv. $)$ dividing the value of $\mathrm{N}_{\mathrm{d}}$ by 1.4 .

Crack openings were calculated for the five levels of forces set out in the calculation spreadsheet. Given that the 
Table 1 Results of technological tests

\begin{tabular}{|c|c|c|}
\hline Tests & Test spots & Results \\
\hline $\begin{array}{l}\text { Determination of the thickness of concrete cover } \\
\text { of the rebar by magnetic induction }\end{array}$ & 110 (11 meshes) & $\begin{array}{l}96.4 \% \text { of the spots analyzed proved to be in accordance with the design } \\
\text { specifications and the currently prevailing standard }(4 \mathrm{~cm})[17]\end{array}$ \\
\hline $\begin{array}{l}\text { Determination of the depth of carbonation of the } \\
\text { concrete }\end{array}$ & 6 & $100 \%$ of the spots analyzed did not present any evidence of carbonation \\
\hline $\begin{array}{l}\text { Determination of the electrical potential of } \\
\text { corrosion of the rebar }\end{array}$ & 5 & $\begin{array}{l}100 \% \text { of the spots analyzed showed a likelihood of corrosion lower than } \\
10 \% \text { according to the Cánovas parameters [4] }\end{array}$ \\
\hline $\begin{array}{l}\text { Determination of the chloride content in relation } \\
\text { to the cement mass }\end{array}$ & 4 & $\begin{array}{l}100 \% \text { of the spots presented chloride content within the regulatory } \\
\text { limits in force, at the time of inspection [15], ranging from } 0.01 \text { to } \\
0.02 \%\end{array}$ \\
\hline $\begin{array}{l}\text { Determination of water absorption by immersion } \\
\text { and boiling }\end{array}$ & 2 & $\begin{array}{l}100 \% \text { of the samples show quality and average absorption according to } \\
\text { the parameters of CEB-FIB [16] }\end{array}$ \\
\hline $\begin{array}{l}\text { Determination of void ratio after saturation and } \\
\text { boiling }\end{array}$ & 2 & $\begin{array}{l}100 \% \text { of the samples show good quality and compactness within the } \\
\text { parameters of CEB-FIB [16] }\end{array}$ \\
\hline $\begin{array}{l}\text { Determination of the resistance to axial } \\
\text { compression of the concrete }\end{array}$ & 7 & $\begin{array}{l}100 \% \text { of the samples have a resistance greater than the design } \\
\text { specification }(30 \mathrm{MPa} \text { ) ranging from } 43.1 \text { to } 70.5 \mathrm{MPa} \text { (average } \\
\text { strength of } 58.2 \pm 9.2 \mathrm{MPa} \text { ) }\end{array}$ \\
\hline Determination of the elasticity modulus & 3 & $\begin{array}{l}\text { The effective secant elasticity modulus proved to be } 5 \% \text { lower than the } \\
\text { estimated modulus according to the specifications of ABNT NBR } 6118 \\
\text { [17] }\end{array}$ \\
\hline $\begin{array}{l}\text { Characterization of expansive reactions } \\
\text { (stereoscopic, optical and electronic microscopy } \\
\text { scanning) }\end{array}$ & 2 & $\begin{array}{l}\text { Reaction edges visible to the naked eye } \\
\text { Deposition of whitish material in the detachment surface of the } \\
\text { aggregate } \\
\text { Potentially reactive coarse aggregate, favoring the occurrence of alkali- } \\
\text { silicate reactions } \\
\text { Presence of quartz with undulating extinction and microgranular quartz } \\
\text { locally recrystallized in the coarse aggregate } \\
\text { Presence of acicular crystals of ettringite in the pores of the concrete } \\
\text { Large amount of typical AAR and ettringite gel } \\
\text { Presence of cracked gel in the mass/aggregate interface and foliar } \\
\text { crystals on the breaking surface of the coarse aggregates }\end{array}$ \\
\hline $\begin{array}{l}\text { Chemical analysis of the water contained in the } \\
\text { reservoir }\end{array}$ & - & $\begin{array}{l}\mathrm{pH} \text { in natura at } 34^{\circ} \mathrm{C} \text { of } 8.2 \\
2.77 \mathrm{mg} / \mathrm{L} \text { of total magnesium } \\
1.28 \mathrm{mg} / \mathrm{L} \text { of sulfates }\end{array}$ \\
\hline
\end{tabular}

first cracks appeared when the reservoir was put into service, the $f_{c k}$ of the project was assumed in the verification of the opening of the cracks.

The values of openings of cracks were calculated according to Eq. 1 specified by ABNT NBR 6118: 2007 [17].

$\mathrm{wk}=\frac{\phi_{\mathrm{i}}}{12.5 \eta_{1}} \frac{\sigma_{\mathrm{si}}}{E_{\mathrm{si}}} \frac{3 \sigma_{\mathrm{si}}}{f_{\mathrm{ctm}}}$

The results obtained are presented in Table 2 .

Note that the value of the opening of cracks goes up to $0.47 \mathrm{~mm}$, exceeding the regulatory limits of $0.2 \mathrm{~mm}$.

Table 2 Results of the calculation of the opening of cracks $w_{k}$

\begin{tabular}{ll}
\hline Level $(\mathrm{m})$ & $\mathrm{w}_{\mathrm{k}}(\mathrm{mm})$ \\
\hline $0-3$ & 0.28 \\
$4-5$ & 0.26 \\
$6-8$ & 0.47 \\
$8-13$ & 0.29 \\
\hline
\end{tabular}

\section{Analysis of the results}

It was found that the reservoir had been designed so that the concrete would have a mechanical resistance and covering of the rebar suitable for the environmental and service conditions, in regard to the parameter of durability.

In fact, it was observed that the structure does not show signs of corrosion of embedded rebars, as indicated by the visual inspection and the test for determining the electric potential of corrosion of the rebars. We could also observe that the concrete has no carbonation or a significant presence of chlorides.

Curiously enough, the good condition of the rebars may have been influenced by the striking infiltration of water suffered by the structure and by the presence of the waterproofing system, which encapsulated the concrete in a pocket of moisture impeding or preventing the penetration of oxygen, essential for the rebars oxidation reactions. 
With regard to this phenomenon, it is emphasized that the optimum moisture content for steel corrosion is between 70 and $80 \%$ [18].

The passage of water through the concrete, however, favors the expansion of the concrete due to the alkali-aggregate reaction and the formation of secondary ettringite. Both expansive reactions, confirmed by the tests, need moisture for their development over time.

The cracking of the concrete due to the alkali-aggregate reaction is generally slow and starts later. According to standard ACI 201-2 [9], it is expected that the fissuration and other effects of the alkali-silica reaction-which includes the alkali-silicate reaction, for the purpose of this analysis-involving certain varieties of quartz, if found in the samples extracted from the reservoir, develop in a time greater than 5 or 10 years and extend over many decades. Thus, it is possible that the current fissuration of the reservoir is not due to this reaction, but that the damage resulting from this may become visible in the coming years.

The fissuration observed, with cracks that are mapped and parallel to the rebars, is probably due to the combination of traction forces resulting from the use of the reservoir too soon after its construction and the specific characteristics of the calculation of the structure with the shrinkage of the concrete. The concrete's high resistance to compression is probably related to a high consumption of cement-the higher the consumption of cement is, the greater the temperature gradients will be during the early stages of the concrete, and the shrinkage suffered by the material will be greater too, causing fissuration. It is noteworthy that, despite the $\mathrm{f}_{\mathrm{ck}} \leq 30 \mathrm{MPa}$ specified in the project, the average resistance of the structure was $58.2 \pm 9.2 \mathrm{MPa}$ and there were spots in which it reached up to $70.5 \mathrm{MPa}$. If one considers the correction coefficients indicated by standard ABNT NBR 7680-1 [19], which entered into force after the analyses were performed, the average resistance becomes $66.3 \pm 10.2 \mathrm{MPa}$ and the maximum resistance remarkably peaks at $79.9 \mathrm{MPa}$. As previously mentioned, there are no technical records about the execution of the work, such as technological control reports or dosage, which might clarify the choice for a mix with resistance so much greater than the $30 \mathrm{MPa}$ used in the calculation of the structure. However, it may be related to putting the reservoir under a load before the 28 days.

If the temperature of the concrete exceeds the temperature of approximately $65{ }^{\circ} \mathrm{C}$ during the occurrence of the hydration reactions, there is still the possibility of retarding the formation of ettringite, one of the components of the concrete. As a result, the formation and expansion of the ettringite, which depend on the moisture of the medium, can occur with the hardened concrete, causing fissuration and exudation of the whitish material, similarly to AAR.
Despite the low sulfate content in the water verified by chemical analysis, the secondary ettringite observed in the samples is probably due also to the intake of sulfates, suggesting that the composition of the wastewater stored in the structure was changed at some point after the structure was put into service.

The contribution of the hydraulic shrinkage and the shrinkage from drying towards the fissuration of the reservoir must be considered, due to the deficient curing of the structure, exacerbated by the quite high temperatures of the region.

The segregation of the concrete that was observed results from failures in the vibration and the densification of the material. This process may have been hindered by the reduced workability of the material, also influenced by the concrete mix and by the temperature of the material and the environment.

The samples used in the tests to determine the resistance to compression, the elasticity modulus of the concrete, the absorption and the void ratio were extracted from regions with no visible anomalies. One may note that they have an average rating as regards absorption, and a good rating in terms of voids, with water percolation taking place mainly through the cracks. It is also possible to note that the expansive reactions did not affect the elasticity modulus of the structure.

The good results obtained in the tests of these samples, if evaluated with the pathological manifestations observed, emphasize the deficient technological control during the execution of the structure.

\section{Discussion}

The conducted study allowed us to observe that the state of degradation of the reservoir is due to inadequate material selection and design, as well as defective execution and maintenance of the structure, with emphasis on the interaction between design and execution teams. As consequence, the reservoir was severely cracked, leaking and presenting expansive reactions (AAR and DEF). Despite being 13 years old, its durability and functionality were compromised since the beginning of operation, which can affect its future stability.

The need to carry out corrective and preventive maintenance works, in this case, is pressing-for if they are not carried out, the degradation of the waterproofing protection system will evolve; the continuous passage of water through the structure favors the leaching of soluble salts of the concrete to the outside of the elements, where they accumulate in the form of efflorescences and concretions. As a result, the concrete is losing mass, becoming more porous and less resistant, its $\mathrm{pH}$ is reduced, and it may 
come to the point of depassivation of the rebars. Under these conditions, if the moisture content of the concrete falls below or near $80 \%$, the embedded rebars may begin to suffer a process of corrosion. Additionally, the fissuration of the reservoir will be intensified by the expansive reactions, which may affect the mechanical properties of the structure and the adhesion between the bars and the concrete, besides further compromising its water-tightness.

Currently, there is no treatment that resolves the alkaliaggregate reaction in a safe and definitive manner. To mitigate it, however, measures such as reducing the moisture in the concrete can be taken. It is important to point out that it is not feasible to completely prevent the contact of the structure with water, as part of it is retained within the elements and the bottom slab is subject to infiltration by capillarity from the humidity present in the soil.

Water is not only essential for the development of AAR, but also for the expansion due to sulfate attack and the corrosion of the rebars. It is expected that the development of expansive reactions generate significant tensile stresses, which can be counteracted through confinements of external structures. For the evaluation of the necessity of such confinements, which are costly, and their dimensions, the use of accelerated tests to determine the residual expansion of the concrete, performed during at least 1 year, may be worthwhile.

It is also essential to clean the structure, to replace the internal waterproofing, to repair the cracks by means of injection, sealing and/or crystallization and the replacement of the outer face protection system by a system that is open to the diffusion of water vapor, allowing the reduction of humidity inside the elements, thus slowing down the expansive reactions.

Since the fissuration presented by the reservoir at the time of inspection is not due to the expansive reactions of the concrete, in general, but that they can lead to serious problems in the years ahead, it is important that the structure be regularly monitored and inspected.

The knowledge of experienced concrete technologists and pathologists, who continuously keep themselves up to date, is essential so that similar failures may be avoided, as well as the revision of paradigms, such as that which confuses high-resistance concrete with high-performance concrete, without distinctions. Due to this, mixes are used which may have resistance to high compression, but are deficient in other properties.

The performance of the concrete must be viewed as a whole, focused on the desired characteristics for the structure-high durability, water-tightness, high workability or high mechanical resistance, for example-jointly defined by the owners or users and the designers, in agreement with those responsible for the execution.
It is of great importance to realize that, even if a highquality concrete may be specified, it is essential that the projects, quality control and construction techniques be up to the same standard, incorporating correct mixture, densification, cure and maintenance procedures, among other things, thus avoiding that a well-defined dosage be compromised by defective production or implementation [20].

We see as the main contributions of this study the practical application of diagnosis techniques, the exposition of several causes of degradation generating similar defects, the exposition of the relations between anomalies in an unusual case of degradation, the demonstration of the importance of the anamnesis of the structure and an alert for the influence of accumulated errors trough the construction and maintenance steps of a structure.

\section{Final considerations}

For a concrete structure to adequately fulfill the functions for which it was designed, it must meet pre-set performance parameters. In the case of reservoirs, these parameters include structural safety, durability and watertightness.

As shown, the reservoir under study shows anomalies that compromise its use because it is not watertight, and its durability, even if the rebars may currently be sound. The occurrence of expansive reactions is particularly worrying, given their evolutionary trend and their highly damaging effects.

Throughout the study, we concluded that several phenomena contributed to the formation of the pathological scenario, as follows:

- Inadequate material selection made the alkali-aggregate reaction possible;

- Execution errors caused fissuration due to shrinkage of the concrete and due to the forces resulting from premature use of the reservoir, and the formation of secondary ettringite due to deficient technological control;

- Inadequate design of the structure resulted in the opening limits of cracks $\left(\mathrm{w}_{\mathrm{k}}\right)$ exceeding regulatory limits;

- Errors in the maintenance work lead to inefficiency of the applied waterproofing system.

Among the factors that originated the state of degradation of the reservoir, we see that the most important was the execution and design errors and the lack of interactions between teams.

We recommend as preventive measures to recover the structure: 
- Cleaning the reservoir;

- Replacing the internal waterproofing;

- Repairing the cracks by means of injection, sealing and/ or crystallization;

- Replacing of the outer face protection system by one that is open to the diffusion of water vapor;

- Regularly monitoring and inspecting the structure to evaluate the development of the expansive reactions.

The reservoir under analysis has an unusual combination of damaging factors, presenting advanced degradation despite its relatively short existence. We consider it to be a significant example of the need for integration between the design and execution teams, the need for keeping detailed records of the stages of execution and especially, the need for the adoption of good practices of design, dosage and execution of concrete structures.

Finally, with regard to the diagnosis, prognosis and specification of therapy for structures affected by pathological manifestations, we emphasize the importance of having a knowledge of the history of the structure and the carrying out of more in-depth studies, based on the analysis of bibliographies, projects and tests, which enables one to avoid simplistic viewpoints and to detect potentially serious problems, such as the occurrence of expansive reactions, in the early stages. As a result, there is the possibility of interventions of lower cost and complexity, thus reducing the operational impact for the owner and the burden for the society.

\section{References}

1. European Standards (2002) EN 1990:2002. Eurocode—basis of structural design. CEN, Brussels

2. Associação Brasileira de Normas Técnicas (2004) NBR 8681. Ações e segurança nas estruturas-procedimento. ABNT, Rio de Janeiro

3. Associação Brasileira de Normas Técnicas (2014) NBR 6118. Projeto de estruturas de concreto-procedimento. ABNT, Rio de Janeiro
4. Cánovas MF (1988) Patologia e terapia do concreto armado, 1st edn, Ed. Pini, São Paulo, p 522

5. American Concrete Institute (2001) ACI 224.1R-07. Causes, evaluation, and repair of cracks in concrete structure. ACI, Farmington Hills

6. Mehta PK, Monteiro PJM (2008) Concreto: microestrutura, propriedades e materiais, 3rd edn. IBRACON, São Paulo, p 674

7. American Concrete Institute (1998) ACI 221.1R-98. State-of-theart report on alkali-aggregate reactivity. ACI, Farmington Hills

8. Associação Brasileira de Normas Técnicas (2008) NBR 15577-1. Agregados-reatividade álcali-agregado. Parte 1: guia para avaliação da reatividade potencial e medidas preventivas para uso de agregados em concreto. ABNT, Rio de Janeiro

9. American Concrete Institute (2008) ACI 201.2R-08. Guide to durable concrete. ACI, Farmington Hills

10. Associação Brasileira de Normas Técnicas (1980) NBR 6118. Projeto e execução de obras de concreto armado. ABNT, Rio de Janeiro

11. Guimarães AEP (1995) Indicações para projeto e execução de reservatórios cilíndricos em concreto armado. Master thesis. São Carlos School of Engineering, Universidade de São Paulo, São Carlos

12. American Concrete Institute (2001) ACI 224R-01. Control of cracking in concrete structures. ACI, Farmington Hills

13. British Standards Institution (1987) BS 8007:1987. Design of concrete structures for retaining aqueous liquids. BSI, London

14. European Standards (2006) EN 1992-3:2006. Eurocode 2-design of concrete structures-part 3: liquid retaining and containment structures. CEN, Brussels

15. Associação Brasileira de Normas Técnicas (2015) NBR 12655. Concreto de cimento Portland-preparo, controle, recebimento e aceitação-procedimento. ABNT, Rio de Janeiro

16. Comité Euro-International du Béton (1989) Diagnosis and assessment of concrete structures-state-of-art report. CEB Bull. CEB, Lausanne

17. Associação Brasileira de Normas Técnicas (2007) NBR 6118. Projeto de estruturas de concreto-procedimento. ABNT, Rio de Janeiro

18. Neville AM (2016) Propriedades do concreto. 5th Edn. Bookman, Porto Alegre, p 912

19. Associação Brasileira de Normas Técnicas (2015) NBR 7680-1. Concreto-extração, preparo, ensaio e análise de testemunhos de estruturas de concreto. Parte 1: Resistência à compressão axial. ABNT, Rio de Janeiro

20. Helene P, Isaia GC, Tutikian BF (2011) Concreto de Alto e UltraAlto Desempenho. In: Isaia _GC (ed) Concreto: Ciência e Tecnologia, Volume II. Edn. IBRACON, São Paulo, pp 1283-1326 